\title{
Molecular Docking study of novel COVID-19 Protease with low risk Terpenoides Compounds of Plants
}

\author{
Neda Shaghaghi \\ Faculty of Science, University of Maragheh, East Azarbaijan, Iran
}

\begin{abstract}
Background :Due to the reported high ability of virulence of COVID_19 in recent months, several studies have been conducted to discover and introduce COVID_19 antiviral drugs. The results of numerous studies have shown that protease inhibitors and compounds, which make up the major part of plant derivatives, especially terpenoids, can therefore be very effective in controlling virus-induced infection. The aim of this research is the bioinformatical study of COVID_19 inhibition by terpenoids of plant origin.
\end{abstract}

Materials and Methods: This is a descriptive-analytic study. In the present study , the structure of terpene comounds and COVID_19 protease was received from the databases such as PubChem and Protein Data Bank (PDB). After that, molecular docking was performed by MVD(molegro virtual docker) software.

Results: The results are identified to have inhibitory activities against novel COVID-19 protease. Of these compounds, Ginkgolide A has a stronger bond and high affinity with protease

Conclusion: Finally, with due attention to the high effectiveness function of terpenoids, we can conclude that these compounds may be considered as effectire COVID_19 antiprotease drugs

Keywords: Coronavirus, Bioinformatic, Terpenoid, Docking

\section{Introduction:}

On 7 January 2020, a new coronavirus, 2019-nCoV (now officially named SARS-CoV-2) was implicated in an alarming outbreak of a pneumonia-like illness COVID-19, originating from Wuhan City, Hubei, China. Human-to-human transmission was first confirmed in Guangdong, China1(Chen et al, 2020). The World Health Organisation has declared this a global public health emergency on 4 March 2020, there are more than 90,000 confirmed 
cases reported, and the death toll is over 3000. In the height of the crisis, this virus is spreading at a rate and scale far worse than previous coronaviral epidemics.

Coronaviruses contain a genome composed of a long RNA strand one of the largest of all RNA viruses. This genome acts just like a messenger RNA when it infects a cell, and directs the synthesis of two long polyproteins that include the machinery that the virus needs to replicate new viruses. These proteins include a replication/transcription complex that makes more RNA, several structural proteins that construct new virions, and two proteases. The proteases play essential roles in cutting the polyproteins into all of these functional pieces. It is a dimer of two identical subunits that together form two active sites. The protein fold is similar to serine proteases like trypsin, but a cysteine amino acid and a nearby histidine perform the protein-cutting reaction and an extra domain stabilizes the dimer. This structure has a peptide-like inhibitor bound in the active site (Cui et al., 2019; John et al., 2015). Bioinformatics is one of the most important and innovative approaches in the design and manufacture of new drugs. Due to the high cost of clinical and laboratory trials, the time consuming and the possibility of error, various bioinformatics techniques are nowadays used in the design of new drugs. Molecular docking, simulation, target point determination and chemical stability studies are the most important bioinformatics methods used in drug design. In the meantime, molecular docking of a special place in the process of designing new drugs, examining and comparing their efficacy Enjoyable (Grinter \& Zou, 2014; Mukesh \& Rakesh, 2011). One of the novel therapeutic strategies for virus infection apart from the design and chemical synthesis of protease inhibitors is the search for inhibitors of this enzyme among natural compounds in order to obtain drugs with minimal side effects.Among these, terpenoids are of particular importance due to their high diversity and low IC50 and presence in plant and microorganisms.Terpenoids are the major secondary plant constituents, with more than 36,000 species reported so far (Augustin et al., 2011) . These compounds have numerous medicinal properties including Anti-cancer (Topcu et al., 2007), Anti-oxidant (del Cerman et al., 1995), Anti inflammatory, antiviral (Nosrati \& Behbahani, 2015), and antibacterial (Angeh et al., 2007).

\section{Method:}

This research was a descriptive-analytical study. In this study, the interaction of terpenic compounds as described in Table 1 was investigated. In order to obtain the 2 and 3 dimensional structure of the compounds, a PubChem database 
(https://pubchem.ncbi.nlm.nih.gov) was used. The PDB database (https://www.rcsb.org/) was used to obtain the complete structure of the protease enzyme.The structure mentioned in access number $\underline{\text { 6lu7 }}$ was received in the PDB database (Liu et al., 2020).

Table 1.Name and structure of the terpenoids studied

\begin{tabular}{|c|c|c|c|}
\hline No. & Compound Name & Source & 2D Structure \\
\hline 1 & Thymoquinone & Nigella sativa & \\
\hline 2 & Salvinorin A & $\underline{\text { Salvia divinorum }}$ & \\
\hline 3 & Bilobalide & $\underline{\text { Ginkgo biloba }}$ & \\
\hline 4 & Citral & $\begin{array}{c}\text { Backhousia } \\
\text { citriodora }\end{array}$ & \\
\hline 5 & Menthol & Mentha & \\
\hline 6 & Ginkgolide A & Ginkgo biloba & \\
\hline
\end{tabular}


7

8

Forscolin

Beta Selinene

9
Papaveraceae

family

Plectranthus

barbatus

Apium

graveolens
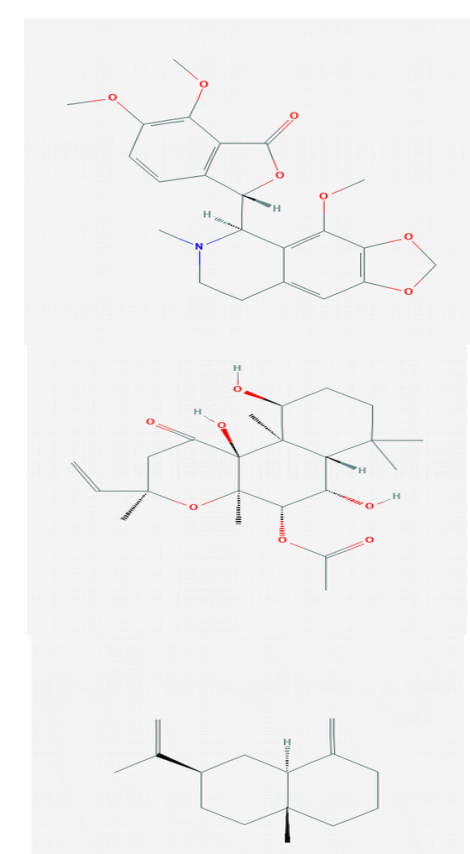

\section{Molecular Docking}

In this study, molecular docking MVD software(https://omictools.com) was used to investigate the molecular interaction between terpene compounds and protease enzyme. This software enables three-dimensional observation of the interaction between terpene and protease enzyme virus of the amino acids participating in the interaction between the functional and functional groups on the terpene molecules. In the present study, all docking conditions for terpene compounds, the number of interactions, the interaction area, the protease enzyme and the rate of docking were considered to minimize error. In this study, molecular docking between terpenoids and protease with the ability to investigate the interaction between hydrogen-electrostatic and van der Waals reactions in the active site of the enzyme was performed and the results were compared. 


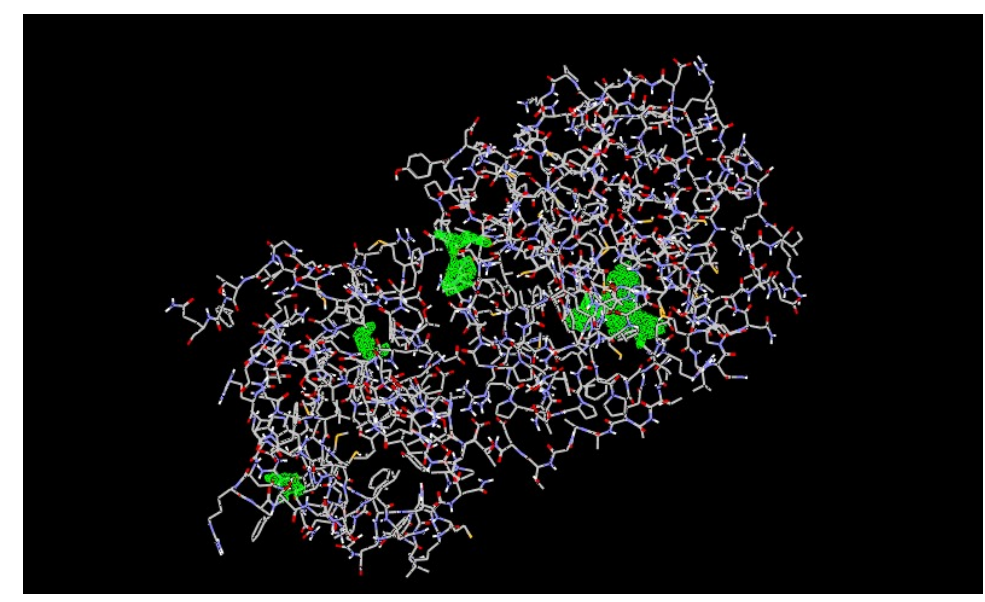

Figure1. Five cavities that are expected to be drug-binding in these protezae.

\section{Result:}

The results of this study indicate the strong interactions of terpenoids in the two enzymatically protected flap regions. Connecting to the above mentioned areas is highly desirable. The results for the binding of these compounds are summarized in Tables 2,3 and 4 . In the meantime binding to several amino acids due to their presence in the conserved region of the active site in all compounds is seen and plays a key role in enzymatic catalysis.

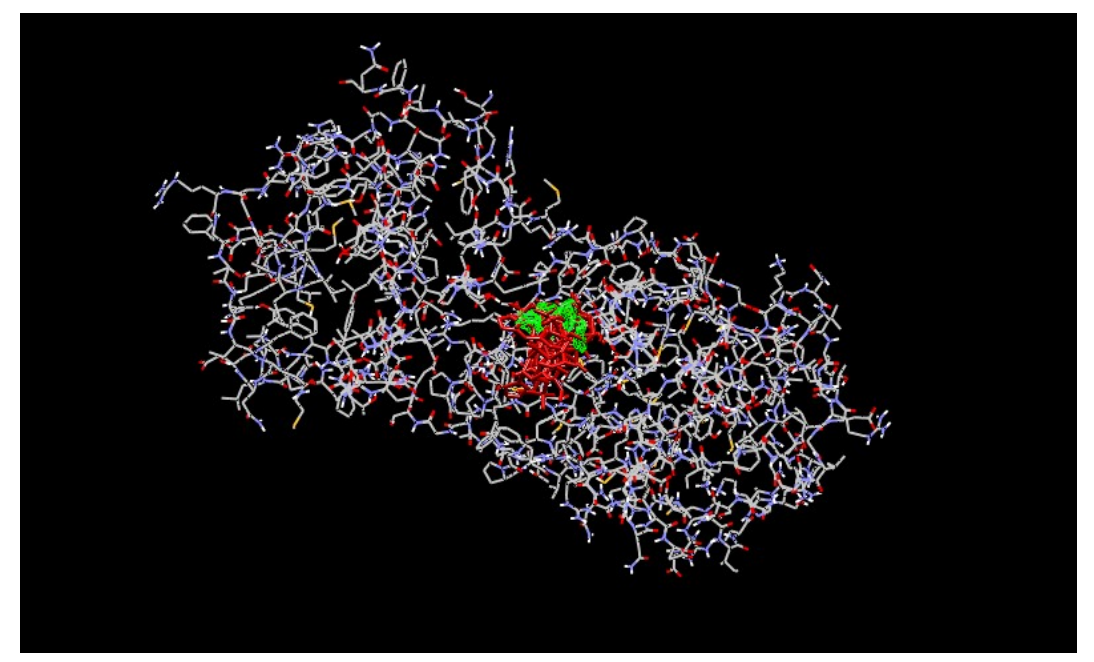

Figure 2. Interactions between the terpene compounds and COVID_19 protease are put into the active site of the protease virus 1

Table 2. The sum of the energies resulting from the interaction of terpenoids and protease enzymes 


\begin{tabular}{|c|c|c|c|c|c|}
\hline No & Compound name & $\begin{array}{c}\text { Tatal } \\
\text { Energy } \\
\end{array}$ & $\begin{array}{l}\text { Ester } \\
\text { Bond } \\
\end{array}$ & $\begin{array}{c}\text { Hydrogrn } \\
\text { Bond } \\
\end{array}$ & $\begin{array}{c}\text { Electrostatic } \\
\text { Bond } \\
\end{array}$ \\
\hline 1 & Thymoquinone & -64 & -57 & -4 & 0 \\
\hline 2 & Salvinorin A & -85 & -101 & -6 & 0 \\
\hline 3 & Bilobalide & -81 & -83 & -5 & 0 \\
\hline 4 & Citral & -67 & -60 & -1.4 & 0 \\
\hline 5 & Menthol & -54 & -54 & -2.4 & 0 \\
\hline 6 & Ginkgolide A & -113 & -118 & -3 & 0 \\
\hline 7 & Noscapine & -98 & -94 & -6 & 0 \\
\hline 8 & Forscolin & -85 & -98 & -5 & 0 \\
\hline 9 & Beta Selinene & -63 & -64 & 0 & 0 \\
\hline
\end{tabular}

Table 3.The amount of binding energy of protease amino acids to terpenoids

\begin{tabular}{|c|c|c|c|c|c|c|c|c|c|c|c|c|c|c|c|c|c|c|c|}
\hline AA & Arg & Asn & Asp & Asp & Cys & Cys & Gln & Gln & Ile & Ile & Lys & Phe & Phe & Phe & Pro & Ser & Thr & Thr & Val \\
\hline Residue ID & 105 & 151 & 153 & 295 & 156 & 160 & 107 & 110 & 106 & 152 & 102 & 8 & 112 & 294 & 293 & 158 & 111 & 292 & 104 \\
\hline Thymoquinone & & -17 & -13 & & & & & -4 & -1.2 & -5.2 & & -1.7 & & -8 & & -4.9 & -0.8 & & -0.8 \\
\hline Salvinorin A & -1.3 & -16 & -15 & -6.7 & -0.5 & & -3.3 & -19 & -5 & -2 & & -5.1 & & -22 & & -1.8 & -9.1 & 4.5 & \\
\hline Bilobalide & & -17 & -8.1 & -2.4 & & -0.5 & & -12 & 1.6 & -4.4 & & -3.8 & -1 & -21 & & -1.6 & -9.2 & -4.3 & -0.9 \\
\hline Citral & & -12 & -12 & -2 & & & & -2 & & -4.8 & & -2.7 & & -15 & & -1.2 & -6 & -0.9 & \\
\hline Menthol & & -17 & -14 & & & & & -0.5 & -0.7 & -5.6 & & -1.2 & & -6.9 & & -6.2 & -0.5 & & -0.9 \\
\hline Ginkgolide A & -3.3 & -16 & -11 & & & -0.4 & -2.2 & -9.7 & -12 & -4.5 & & -2.2 & -0.4 & -8.9 & & -3.2 & 0.9 & & -5.8 \\
\hline Noscapine & -4.4 & -11 & -5.6 & -3.3 & & -0.4 & -3.4 & -15 & -14 & -0.9 & & -1.2 & & -19 & -0.7 & -4 & -4.4 & -5.3 & -2.6 \\
\hline Forscolin & -1 & -19 & -14 & -3.9 & -0.5 & & -2.5 & -18 & -3 & -6.6 & -0.4 & -1.2 & & -16 & & -3.1 & -5.6 & -2.3 & -2.3 \\
\hline Beta Selinene & & -15 & -13 & -0.6 & -0.4 & & & -2.7 & & -4.4 & & -2.4 & & -17 & & -3.3 & -0.7 & -0.8 & \\
\hline
\end{tabular}

Table4. The amount of energy of hydrogen bind in compounds with water

\begin{tabular}{ccccccc}
\hline & HOH 408 & HOH 417 & HOH 440 & HOH 456 & HOH 463 & HOH 479 \\
\hline Residue ID & $\mathbf{7}$ & $\mathbf{1 6}$ & $\mathbf{3 9}$ & $\mathbf{5 5}$ & $\mathbf{6 2}$ & $\mathbf{7 8}$ \\
Thymoquinone & & -4.2 & -3.8 & & -1.8 & \\
Salvinorin A & -2.5 & -2.4 & 6.8 & -0.78 & -0.4 & -2 \\
Bilobalide & -1.6 & -1.5 & 7 & -0.4 & -5 & \\
Citral & -3.2 & -0.9 & 1.7 & & -0.4 & \\
Menthol & & & -1.5 & & -1.7 & \\
Ginkgolide A & & -7.2 & -7.3 & & -3.8 & -0.7 \\
Noscapine & -0.5 & -2.9 & -0.5 & 2.8 & -3 & -0.7 \\
Forscolin & -1.2 & -3.9 & -2.7 & -0.5 & -4.5 & -1.2 \\
Beta Selinene & & -1.9 & -1.6 & -1.1 & -1.6 & \\
\hline
\end{tabular}



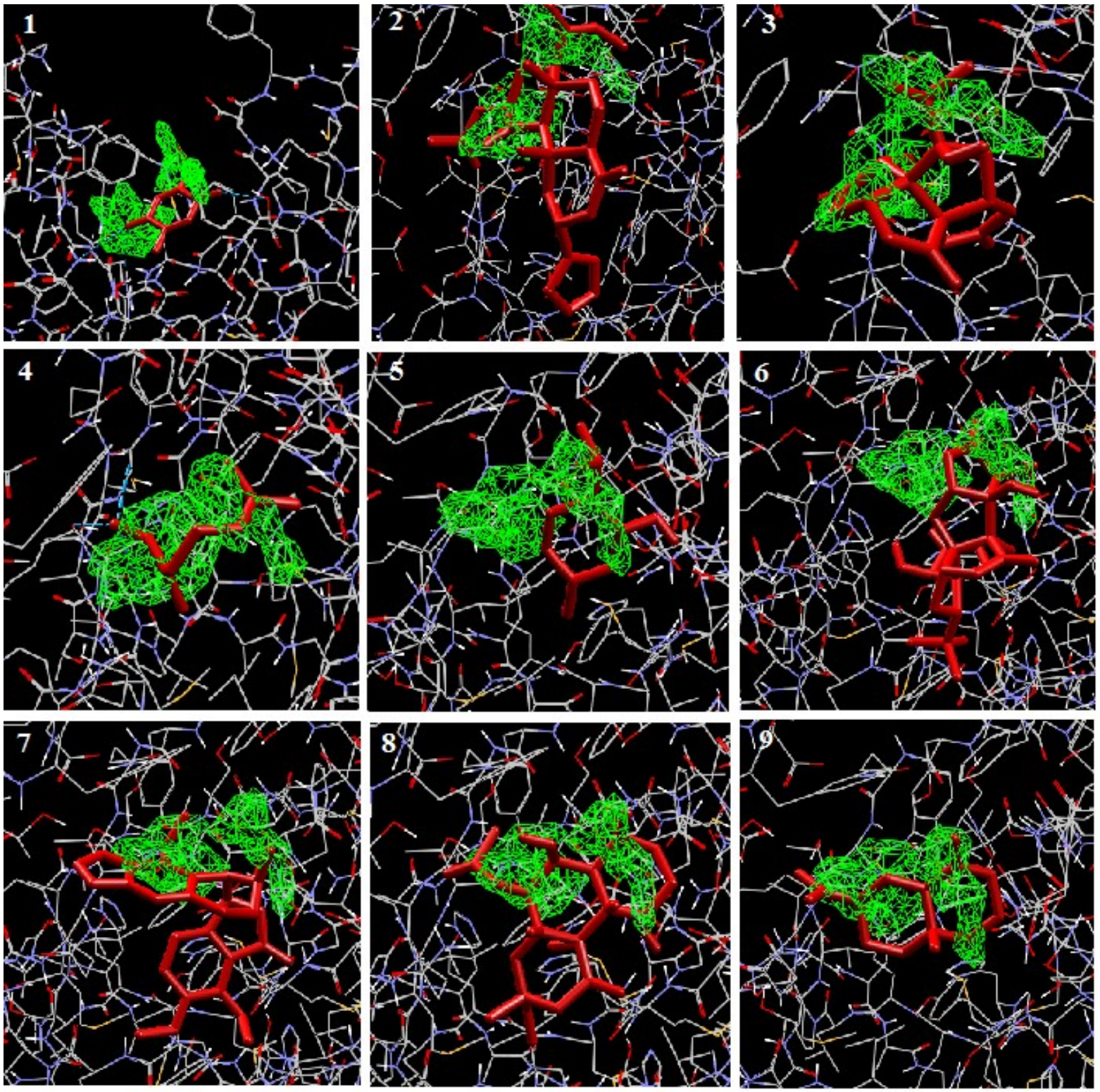

Figure 2.The interaction between terpene compounds in the active site of the protease enzyme virus. 1:Thymoquinone, 2:Salvinorin A, 3:Bilobalide, 4:Citral, 5:Menthol, 6:Ginkgolide A, 7:Noscapine, 8:Forscolin, 9:Beta Selinene

\section{Discussion:}

In this study, I used the recently released crystal structure of COVID-19 proteinase and lowrisk or safe herbal medicines for docking analysis. The results of this study showed that the terpenoids studied can effectively inhibit the virus protease. These compounds can effectively inhibit these amino acids during the catalytic process by interacting with the key amino acids active site. The software identified five protected areas of the enzymatic flap. The terpenoids 
studied in this research had strong binding affinities with two enzymatic flaps and formed the strongest bonds with the amino acids Asparagine151, Aspartate153 and Phenylalanine8.These three amino acids are in the highly conserved and catalytic region of the enzyme. So, low-risk drugs can be designed to bind to these three amino acids.Therefore, due to the strong interaction of natural terpene compounds with enzymatically conserved regions and specific functional ability, these compounds can be introduced as effective anti-drugs due to their natural origin and less likely to cause side effects if the interactions are enhanced. During chemical processes and microbial biodegradations can be suitable substitutes for synthetic drugs. People are also more likely to take herbal remedies because they have fewer side effects; So it is best to focus on these drugs to treat new coronavirus infections

\section{Conclusion:}

Based on the results of the present study, it can be concluded that the investigated terpenoids can interfere with the important amino acids in the enzymatic cavity to inhibit the protease enzyme virus. Nine neutral drugs and low risk, namely, Thymoquinone, Salvinorin A, Bilobalide, Citral, Menthol, Ginkgolide A, Noscapine, Forscolin, Beta Selinene are identified to have inhibitory activities against novel COVID-19 protease. Of these compounds, Ginkgolide A has a stronger bond and high affinity with protease.

\section{References:}

Andersen, N. H., Christensen, N. J., Lassen, P. R., Freedman, T. B., Nafie, L. A., Strømgaard, K., \& Hemmingsen, L. (2010). Structure and absolute configuration of ginkgolide B characterized by IR-and VCD spectroscopy. Chirality: The Pharmacological, Biological, and Chemical Consequences of Molecular Asymmetry, 22(2), 217-223.

Angeh, J. E., Huang, X., Swan, G. E., Mollman, U., Sattler, I., \& Eloff, J. N. (2007). Novel antibacterial triterpenoid from Combretum padoides [Combretaceae].

Attokaran, M. (2011). Natural food flavors and colorants, chap 68: Blackwell Publishing Ltd. and Institute of Food Technologists, Ames, IA.

Augustin, J. M., Kuzina, V., Andersen, S. B., \& Bak, S. (2011). Molecular activities, biosynthesis and evolution of triterpenoid saponins. Phytochemistry, 72(6), 435-457.

Baell, J. B. (2016). Feeling nature's PAINS: natural products, natural product drugs, and pan assay interference compounds (PAINS). Journal of natural products, 79(3), 616-628.

Chen, Y., Liu, Q., \& Guo, D. (2020). Emerging coronaviruses: genome structure, replication, and pathogenesis. Journal of medical virology. 
Chen, Y. W., Yiu, C.-P. B., \& Wong, K.-Y. (2020). Prediction of the SARS-CoV-2 (2019-nCoV) 3Clike protease (3CL pro) structure: virtual screening reveals velpatasvir, ledipasvir, and other drug repurposing candidates. F1000Research, 9(129), 129.

Cui, J., Li, F., \& Shi, Z.-L. (2019). Origin and evolution of pathogenic coronaviruses. Nature reviews Microbiology, 17(3), 181-192.

del Carmen Recio, M., Giner, R. M., Máñez, S., \& Ríos, J. L. (1995). Structural requirements for the anti-inflammatory activity of natural triterpenoids. Planta Medica, 61(02), 182-185.

Eccles, R. (1994). Menthol and related cooling compounds. Journal of Pharmacy and Pharmacology, 46(8), 618-630.

Fenaroli, G. (1975). Fenaroli's handbook of flavor ingredients (Vol. 1): Taylor \& Francis.

Grinter, S. Z., \& Zou, X. (2014). Challenges, applications, and recent advances of protein-ligand docking in structure-based drug design. Molecules, 19(7), 10150-10176.

Hilgenfeld, R. (2014). From SARS to MERS: crystallographic studies on coronaviral proteases enable antiviral drug design. The FEBS journal, 281(18), 4085-4096.

John, S. E. S., Tomar, S., Stauffer, S. R., \& Mesecar, A. D. (2015). Targeting zoonotic viruses: Structure-based inhibition of the 3C-like protease from bat coronavirus HKU4-The likely reservoir host to the human coronavirus that causes Middle East Respiratory Syndrome (MERS). Bioorganic \& medicinal chemistry, 23(17), 6036-6048.

Li, Y., Zhang, J., Wang, N., Li, H., Shi, Y., Guo, G., . . Zou, Q. (2020). Therapeutic Drugs Targeting 2019-nCoV Main Protease by High-Throughput Screening. bioRxiv.

Liu, X., Zhang, B., Jin, Z., Yang, H., \& Rao, Z. (2020). The Crytal Structure of 2019-NCoV Main Protease in Complex with an Inhibitor N3. RCSB Protein Data Bank.

MacLean, K. A., Johnson, M. W., Reissig, C. J., Prisinzano, T. E., \& Griffiths, R. R. (2013). Doserelated effects of salvinorin A in humans: dissociative, hallucinogenic, and memory effects. Psychopharmacology, 226(2), 381-392.

Mukesh, B., \& Rakesh, K. (2011). Review on Molecular docking. Ijrap, 2(6), 1746-1751.

Nosrati, M., \& Behbahani, M. (2015). Molecular Docking Study of HIV-1 Protease with Triterpenoides Compounds from Plants and Mushroom. Arak Uni Med Sci J, 18(3), 67-79.

Topcu, G., Ertas, A., Kolak, U., Ozturk, M., \& Ulubelen, A. (2007). Antioxidant activity tests on novel triterpenoids from Salvia macrochlamys. Arkivoc, 7, 195-208.

van Beek, T. A., \& Montoro, P. (2009). Chemical analysis and quality control of Ginkgo biloba leaves, extracts, and phytopharmaceuticals. Journal of Chromatography A, 1216(11), 2002-2032.

Wang, M., Cao, R., Zhang, L., Yang, X., Liu, J., Xu, M., . . Xiao, G. (2020). Remdesivir and chloroquine effectively inhibit the recently emerged novel coronavirus (2019-nCoV) in vitro. Cell research, 1-3.

Xu, Z., Peng, C., Shi, Y., Zhu, Z., Mu, K., Wang, X., \& Zhu, W. (2020). Nelfinavir was predicted to be a potential inhibitor of 2019-nCov main protease by an integrative approach combining homology modelling, molecular docking and binding free energy calculation. bioRxiv. 